\title{
O Filme Capote: abordagens sobre os espaços público e privado
}

Carla ReIs LonghI 


\section{Resumo}

A autora deste artigo analisa os imbricamentos entre os espaços público e privado no séc. XX, através da abordagem do Filme Capote. Retomando a relação autor - fato - obra, recorrente neste filme, estabelecemos um diálogo com Hannah Arendt e Jürgen Habermas, buscando a compreensão da reconceituação destes espaços e suas conseqüências para a condição humana.

\section{Palavras-chave}

Espaços público e privado; condição humana.

\section{Abstract}

The author of the article analyses the relationships between private and public spaces in twenty century as represented in the film Capote. The triangle of the author- fact- literary work established in this film entrances a dialogue with Hannah Arendt and Jurgen Habermas, leading to a better comprehension of the meantioned spaces and the consequences of these conceptions in human condition.

\section{Key words}

Private and public spaces, human condition. 


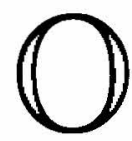

filme Capote, vencedor do Oscar de melhor ator em 2005, fornece uma versão da elaboração do livro 'A Sangue Frio" de Truman Capote. A narração apresenta um longo processo de construção da informação, inicialmente pensada para a confecção de um artigo para o jornal para o qual trabalhava e, depois, transformada em material para a confecção do livro, de autoria própria. Retrata, com densidade, uma complexa triangulação autorfato- obra, propiciando uma vasta discussão sobre as fronteiras entre os interesses contidos na esfera pública, representados pelo jornal(ismo), como meio de coesão social e os interesses privados, explicitados nos conflitos e conduta do jornalista e escritor Truman Capote, discussão esta que será o objeto de nosso artigo.

Capote lê uma notícia de jornal sobre o assassinato de uma família, ocorrido em uma pequena cidade do Estado de Kansas, Estados Unidos e, instigado pela mesma, resolve ir até o local, acompanhado de sua assistente Nelle Harper Lee, para averiguar, com seus próprios olhos, os procedimentos da polícia local e o contexto do crime. Em sua estada na cidade, o crime é solucionado mas, o contato com os assassinos, em particular com Perry, inicia o longo processo de construção do livro, marco do jornalismo literário. Neste percurso, o interesse de Truman em captar as sensações dos autores do crime e as motivações para tal ato, revela os limites do jornalismo, percorrendo de modo fluido interesses públicos e privados, desnudando as motivações mais íntimas do próprio autor. 


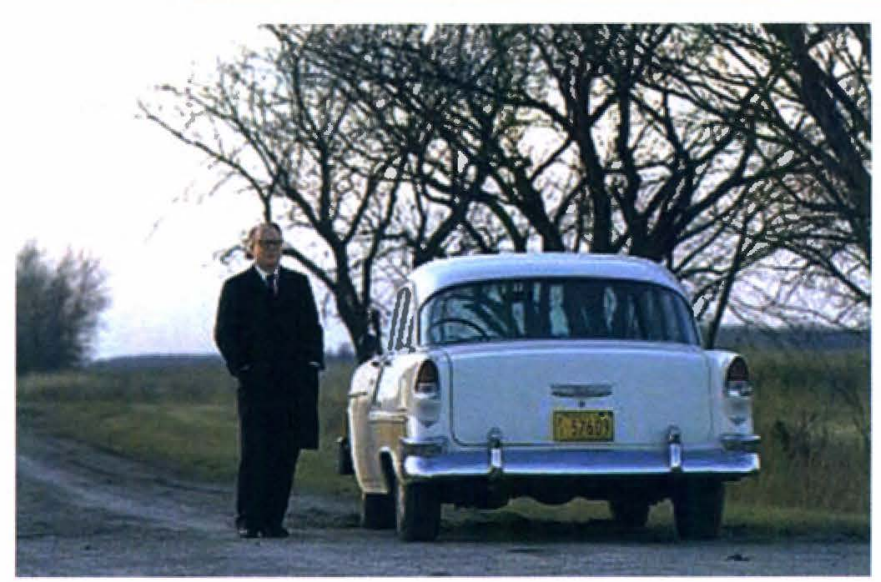

Fig. 1- Cena do Filme Capote

Truman Capote chega à cidade como representante do jornal e sai representando seus interesses privados indicando, através do filme, para uma questão discutida hoje no jornalismo: o compromisso jornalístico. O próprio ponto de partida de atuação do jornalista, marcado pelo conflito do agir motivado pelos seus valores ou pela ação racional, já representaria, historicamente, um delimitador fundamental deste compromisso. (Contrera, 2004, p.11)

Esta inversão de sentido realizada pelo jornalista não indica uma crise do papel do jornalismo, tampouco novos significados para o fazer jornalístico. Isto por que, no filme, Capote decide escrever um livro, transformando ai o significado da informação obtida. Neste momento, assume, duplamente, a responsabilidade da autoria, pois não necessita legitimar o próprio jornal e passa a ter a liberdade estilística, o que lhe confere ineditismo do perfil da nova publicação. Ao mesmo tempo, o fazer jornalístico engendrado a partir de interesses públicos e privados tem, em sua origem burguesa, a marca da autoreferência. Esta classe moldou uma esfera pública, desvinculada de discussões de sentido público, como forma de ascensão ao espaço público, denominada por Habermas de esfera pública literária. No séc. XVIII, a burguesia, apesar de ser o agente econômico, estava cerceada politicamente. Este setor passa a ocupar a sociedade, apropriando-se do modelo de ocupação fornecido pela própria corte. Assim, inicialmente, apenas a alta burguesia co-participa dos fóruns 
sociais: as apresentações de teatro, as recepções artísticas. Com o tempo, esta mesma burguesia, alimentada por seus próprios intelectuais, organiza os seus encontros, disseminados com a proliferação dos cafés. Inicialmente são reuniões literárias:

Raramente algum dos grandes escritores do século XVIII havia deixado de colocar primeiro em discussão as suas idéias essenciais em tais discours, ou seja, em palestras perante as academias e, sobretudo, nos salões. O salon mantinha simultaneamente o monopólio da primeira edição: uma nova obra, mesmo sendo musical, tinha de primeiro legitimar-se perante este fórum. (Habermas, 1984, p. 49)

Notemos pela transcrição acima, que a forma de inserção no cenário público, proposta e possível à burguesia, grupo este composto de pessoas privadas, pois estavam impedidas de participar das funções do Estado e estavam orientadas por interesses privados, foi à criação de uma esfera de ascensão ao público, que não significava acesso aos instrumentos de ação política: governo, leis, controle da burocracia ou da polícia, constituindo, outrossim, um espaço de aparência para reverberar a posição definida pelo fórum sobre questões culturais. Assim, este é um espaço literário e representativo. Contudo, percebemos nesta construção, uma reordenação do sentido de representação, pois há um progressivo distanciamento da produção cultural como espaço de representação da corte, ou seja, da reprodução de valores a serem seguidos, entendimento este que vigorou até este momento. Há, nesta passagem, a libertação da produção cultural, que não precisa mais seguir os rigores do grupo que representava, mas por outro lado, ao se tornar bem cultural moldado pelo modo burguês de inserção social, não só modifica o significado de representação, como também, ascende às regras do mercado. Como resultado, houve um longo processo de transformação da produção cultural em bem de consumo definindo, ao mesmo tempo, a conformação de um espaço legitimado, pois representativo. São criados os critérios de legitimação desta nova configuração de 
representação: a opinião pública. Este conceito, em sua origem, se caracteriza como a conexão que alinhava a tessitura social. Ele está no espaço público literário, neste sentido, espaço não político, mas também não privado. Assim, se constituiu no intuito de possibilitar o ato comunicativo, interligando público e privado.

O homem burguês que lia os romances, os folhetins e os jornais, buscava nos salões a reflexão sobre o seu pensar de classe, mediado pela publicação das idéias circulantes. Desta forma, a proliferação dos meios de comunicação garante à constituição de um aparato que perceba e propague as idéias propostas. Assim, para garantir a visibilidade por um lado, e a representação, por outro, ou seja, para criar vínculos de comunicação, houve a proliferação dos jornais impressos e das revistas, originando a prática da opinião pública, 'coesão', efetivada no espaço público não político. O caráter autoreferencial e não político apresentava-se como uma face da definição de opinião pública, complementada pela sua outra face, a do papel de circulação da cultura, mediada pela palavra falada e escrita. Esta composição caracterizava a esfera literária e, conseqüentemente, a própria opinião pública. Assim, esta se definia como a 'liga' entre os espaços privado e público.

Ao mesmo tempo, essas novas revistas estão ligadas tão intimamente com a vida dos cafés que ela poderia ser reconstruida através de cada número. Os artigos de jornais não só são transformados pelo público dos cafés em objeto de suas discussões, mas também entendidos como parte integrante deles; isto se mostra no dilúvio de cartas, das quais os editores semanalmente publicavam uma seleção (...) Também a forma de diálogo, que muitos artigos mantêm, testemunha a proximidade da palavra falada. Transporta para um outro meio de comunicação, continua-se a mesma discussão para, mediante a leitura, reingressar no meio anterior, que era a conversação. (Habermas, 1984, p.59)

Esta caracterização original que vinculava opinião pública à palavra falada privilegiava dois importantes aspectos próximos, mas 
não correlatos: primeiro o que chamamos hoje de mídia primária, ${ }^{\prime}$ ou seja, a utilização da comunicação presencial, feita com o nosso corpo, estabelecendo vínculos com pessoas próximas; segundo, a construção contínua da ação (a expressão do pensar pela palavra ou pelo ato) mediada pelo Outro. Ambas sofrerão transformações modificando, também, a caracterização da esfera na qual estavam instituídas. Capote apresenta a proposta de seu livro para um público selecionado. Apesar desta comunicação se dar através da mídia primária, a relação autor- público transforma-se, como bem retratou Habermas:

Por outro lado, a tendência para o debate público também continua. Organizam-se, formalmente, os assim chamados 'debates' $e$, como parte integrante da pedagógica formação dos adultos, eles são ao mesmo tempo departamentalizados. Seminários religiosos, fóruns políticos, organizações literárias vivem dos debates sobre uma cultura que pode ser discutida e precisa ser comentada; emissoras de rádio, editoras, associações, desenvolvem, com as discussões públicas, uma florescente atividade secundária. Com isso, a discussão parece sujeita a grandes cuidados e não parecem existir limites à sua expansão. Por baixo do pano, no entanto, ela se alterou de modo peculiar: ela mesma assume a configuração de bem de consumo.(...) A discussão, incluída no 'negócio', formaliza-se; posição $e$ contraposição estão de antemão sujeitas a certas regras da apresentação; o consenso na questão torna-se grandemente supérfluo devido ao consenso do procedimento. (1984, p.193/194)

Aqui, o homem já não precisa falar. Habermas demonstra que este passo mostrou-se como reflexo da inserção do bem cultural, como bem mercadológico. $\mathrm{O}$ ato do consumo prescinde da fala. Nesta reconceituação tão bem apropriada pelas mídias de massa, a opinião

1. José Eugenio de $O$. Menezes desenvolve este conceito no texto “ Incomunicação e Mídia” IN BAITELLO JUNIOR et alli (org) Os Meios da Incomunicação. 
pública não é mais vínculo, pois desconsidera a comunicação pública, típica de sua caracterização original. A discussão também se transforma em bem de consumo e, em função disso, recebe cuidados que a engessa: passa a ser produzida, seguindo regras de organização, constituída como consenso. Capote cria uma performance para chegar ao público; percebe-o, escolhe as palavras e os gracejos. Criam-se conexões e não vínculos.

Eles cativam o público enquanto ouvinte e espectador, mas ao mesmo tempo tiram-lhe a distancia da 'emancipação', ou seja, a chance de poder dizer e contradizer. O raciocínio de um público-leitor dá tendencialmente lugar ao 'intercâmbio de gostos $e$ preferências' de consumidores-inclusive o falar sobre o consumido, 'a prova dos conhecimentos do gosto', tornase parte do consumo. (Habermas, 1984, p.202)

O papel definido à palavra falada e o seu diálogo com a palavra escrita é transformado. A cultura como mercadoria é parte de um longo processo de remodelação das intersecções entre as esferas pública e privada. O séc. XIX configurou um novo reordenamento destas esferas. Houve a sobreposição das esferas social e pública (política). È um golpe definitivo para a tentativa de se visualizar as distinções entre elas. Aqui, a esfera social assume funções públicas, como por exemplo, na configuração dos sindicatos (instituições de cunho privado) que passam a gerenciar acordos coletivos de trabalho. Ao mesmo tempo, o Estado passa a interferir nas regras de convivência das esferas social e privada, passando a legislar sobre a família, a definir direitos do consumidor, etc. Esta nova ordenação é requerida pela própria sociedade, pois, a massa que ascendeu à esfera pública, necessita de respaldo legal para esta inserção, na defesa de direitos mínimos frente ao poder dos setores político-econômicos já estabelecidos. Esta diluição de fronteiras visíveis para as várias esferas não se configura sem perdas.

Quando tomamos o conceito de público em seu sentido original, discutido por Hannah Arendt, notamos a composição de quatro distintos 
aspectos: em primeiro lugar, público denota tudo aquilo que pode ser visto e ouvido por todos, havendo forte divulgação. “Em segundo lugar, o termo 'público' significa o próprio mundo, na medida em que é comum a todos nós e diferente do lugar que nos cabe dentro dele. " Do nosso ponto de vista, dois outros aspectos são fundamentais para pensarmos estas composições em nossa sociedade:

A excelência em si, 'arete' como a teriam chamado os gregos, 'virtus' como teriam dito os romanos, sempre foi reservada à esfera pública, onde uma pessoa podia sobressair-se e distinguir-se das demais. Toda atividade realizada em público pode atingir uma excelência jamais igualada na intimidade; para a excelência, por definição, há sempre a necessidade da presença de outros, e essa presença requer um público formal, constituido pelos pares do individuo; não pode ser a presença fortuita e familiar de seus iguais ou inferiores (...). (Arendt, 2000, p.58)

Para o homem grego, tudo que era público, ou seja, estava disponibilizado para ser visto e ouvido, deveria buscar a excelência, pois somente a permanência do mundo, entendido como uma comunidade de elementos que se estabelecem entre os homens e permitem as relações entre os mesmos, possibilita a existência do espaço público. Desta forma, era consenso para o homem grego que a sua própria existência, na relação com o Outro, necessitava de uma esfera comum, reforçando a constante busca pela excelência, ou seja, a permanência dos atos e idéias após a morte do corpo. Esta pré-condição garantia à esfera pública, como coloca Hannah Arendt, a condição de espaço da mais profunda igualdade para a realização da mais intensa diversidade:

... mas a esfera pública em si, a polis, era permeada de um espirito acirradamente agonístico: cada homem tinha constantemente que se distinguir de todos os outros, demonstrar, através de seus feitos ou realizações singulares, que era o melhor de todos (aien aristeuein). (2000, p.51) 
Este feito precisava acontecer entre iguais, definindo um público interlocutor que, em nada seria aleatório. Vemos que não havia interlocutor para Capote, mas sim ouvintes. Além disso, as intenções do autor eram muito distintas da busca da excelência. $\mathrm{Na}$ fala do ator, representando Capote, emerge a intensa subjetividade, como fator mobilizador de sua ação:

É como se Perry e eu tivéssemos crescido na mesma casa. E um dia, ele tivesse se levantado e saido pela porta dos fundos enquanto eu saía pela porta da frente (...) não somos tão diferentes assim. (fala proferida pelo personagem Truman Capote numa das cenas do filme Capote)

Capote chegou à cidade legitimado pelo jornal no qual trabalhava e inicialmente estava profundamente interessado em compreender as motivações do assassinato. Esta demanda o aproxima de Perry, mas seus encontros se transformam em interesse pessoal. $\mathrm{O}$ jornalista/ escritor se interessa pelo assassino: como homem, como ser humano e como ponte para a sua vaidade. Os tênues limites do interesse público foram abalados. Trumam Capote passa a nutrir (no filme) um profundo interesse pela compreensão das motivações daquele assassino que estava à sua frente. Passa a freqüentar sua cela no intuito de obter uma exata descrição da cena do assassinato. Esta motivação o leva a contratar os melhores advogados, a fim de garantir a postergação da morte do preso. È feliz em sua tentativa, garantindo anos de sobrevida ao homem que não lhe fornece a narrativa.Temos aqui o exemplo da última fronteira devassada: a esfera íntima. Tais quais os limites do público e do privado, bem como do social foram esfumaçados, perdendo a nitidez, esta esfera também o foi. O Homem contemporâneo mantém a ilusão de que possui uma intimidade protegida e livre, mas nossa sociedade se encarregou de escancará-la, ao levar as questões privadas para a visibilidade pública. Até a vivência do tempo do lazer ascendeu à coletividade, através dos clubes, resorts, condomínios fechados ou dos prédios de apartamentos. Nestes últimos, a intimidade é constantemente vigiada, através do controle de todos os sons proferidos, em função da 
existência de paredes tão finas, que não são as grades da cela de Perry, mas cumprem o mesmo papel. Vemos que os interesses de Capote correspondem a um percurso social.

De um profundo interesse em esquadrinhar aquela alma, seguido de um certo desejo, Capote passa a sentir-se pressionado, perseguido pela continuidade da existência daquele ser, sentindo-se deprimido, partindo para ações intempestivas, como cortar o pagamento dos advogados. A vida de Perry, que inicialmente garantia o seu deleite, passa a inviabilizar a sua própria realização: o desfecho do livro. Dois distintos aspectos demarcam esta passagem: as suas motivações e a temática que lhe causa interesse. As motivações, muito distante da busca de excelência, significam a realização fugaz, a busca do fortuito, que é a admiração pública:

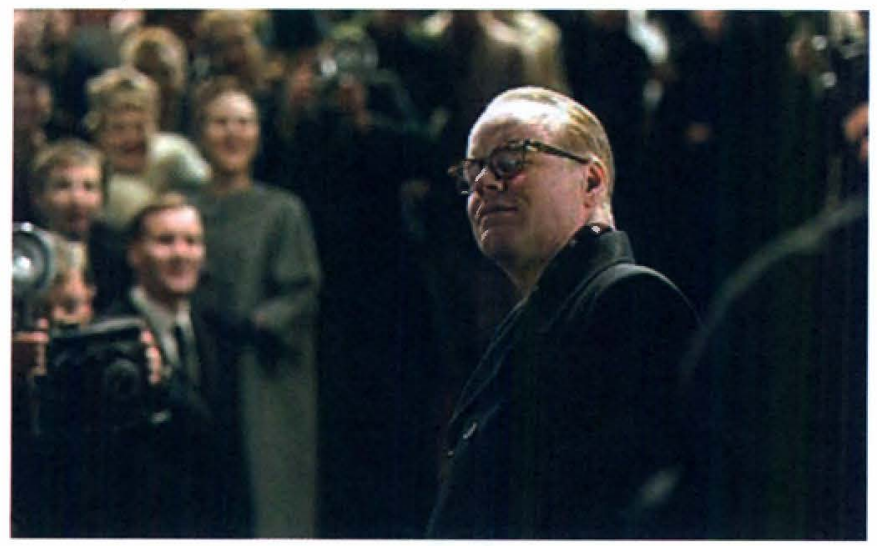

Fig. 2: Filme Capote

Nestas palavras fica evidente que a admiração pública e a recompensa monetária têm a mesma natureza e podem substituir uma à outra. A admiração pública é também algo a ser usado e consumido; e o status, como diriamos hoje, satisfaz uma necessidade como o alimento satisfaz outra: a admiração pública é consumida pela vaidade individual da mesma forma como o alimento é consumido pela fome. Obviamente, deste ponto de vista, a prova da realidade não está na presença pública de outros , mas 
antes na maior ou menor premência das necessidades, cuja existência ou inexistência ninguém pode jamais atestar senão aquele que as sente. (Arendt, 2000, p. 66)

Estas motivações equivalem às necessidades do labor, são as premências da vida, pois são realizadas para a existência vital. $\mathrm{O}$ que é consumido pelo homem, é feito para a completude do corpo, para saciar o corpo e/ ou a alma e, neste sentido, realiza a própria existência, estando no campo da necessidade. Esta precisa da presença do Outro para a própria realização, tal qual o ato sexual, que se dá para realização dos prazeres individuais e, sua manutenção só se efetiva durante a realização do ato. Neste sentido, não há permanência, pois o resultado é consumido como objeto de prazer.

O que distinguia a esfera familiar era que nela os homens viviam juntos por serem compelidos por suas necessidades e carência. A força compulsiva era a própria vida_os penates, os deuses do lar, eram segundo Plutarco, 'os deuses que nos fazem viver e alimentar o nosso corpo'; e a vida, para sua manutenção individual e sobrevivência como vida da espécie, requer a companhia de outros. (Arendt, 2000, p.39/40)

Aliado a este aspecto, precisamos considerar as temáticas que preenchem os espaços público e privado. Capote diz, ao se referir ao assassino: "Não somos tão diferentes quanto você pensa". Nesta frase, mais uma vez indica o objeto de seu interesse: a própria subjetividade pois, ao buscar razões para o assassinato, busca razões para os seus próprios atos. Estas são questões próprias da esfera privada, pois por um lado, expressam a subjetividade, aspecto privado, íntimo e, por outro lado, são tão fugazes como o que as motiva, a vaidade.

Após o declínio de sua vasta e gloriosa esfera pública, os franceses tornaram-se mestres da arte de serem felizes entre 'pequenas coisas', dentro do espaço de suas quatro 
paredes, entre o armário e a cama, entre a mesa e a cadeira, entre o cão, o gato e o vaso de flores, dedicando a estas coisas um cuidado e uma ternura que, num mundo em que a rápida industrialização destrói constantemente as coisas de ontem para produzir os objetos de hoje, pode até parecer o último recanto puramente humano do mundo. Esta ampliação da esfera privada, o encantamento, por assim dizer, de todo um povo, não a torna pública, não constitui uma esfera pública, mas ao contrário, significa apenas que a esfera pública refluiu quase inteiramente, de modo que, em toda parte, a grandeza cedeu lugar ao encanto; pois embora a esfera pública possa ser grande, não pode ser encantadora precisamente porque é incapaz de abrigar o irrelevante. (Arendt, 2000, p.62)

As conseqüências visíveis da ascensão ao espaço público são a aparência e a concretização do mundo. Estes dois conceitos, na Grécia antiga, se realizavam e eram costurados pela ação, pois os homens se reuniam numa mesma esfera para tomar decisões sobre um aspecto exterior a eles próprios: a cidade e sua relação com os outros povos. As questões propostas eram públicas duplamente. Por um lado, não expressavam pensamentos delineados pela subjetividade e auto-referência e, por outro lado ou por isso mesmo, eram idéias e práticas que tinham continuidade para a existência da cidade. A permanência é o que pode realizar continuamente o mundo para os homens que ascendem à esfera pública. São os parâmetros de sua existência, contidos em sua história, na tradição que lhe diz de onde vem e lhe caracteriza enquanto sujeito.

"Se eu sair daqui sem lhe entender, o mundo te verá como um monstro, sempre, e eu não quero isso". (fala de Capote), aliada a frase já transcrita "Não somos tão diferentes quanto você pensa." (Frase proferida pelo ator Philip Seymour Hoffman no papel de Truman Capote- Filme Capote). 
Na fala de Capote, em contraposição à noção de público, há a expressão de seus próprios sentimentos, do escrutínio da intimidade humana, das razões mais íntimas, menos perceptíveis e, menos concretas. Por mais que ele as traduza em palavras, materializadas em seu livro, os sentimentos jamais poderão ser revividos e sentidos do mesmo modo e, nenhum leitor terá o elemento comparativo de sua percepção em relação à do autor, e de fato, isto não é objeto e intenção de um texto literário. Mas o livro de Capote não é plenamente literário, é também investigativo e se propõe a elucidar aspectos de um fato ocorrido. Aqui há o claro imbricamento de questões públicas e privadas tratadas no mesmo objeto. A sutileza está no fato de que o que motiva o aprofundamento da pesquisa, o investimento na continuidade da vida daquele assassino é a curiosidade sobre a intimidade humana. Esta mobilização está perdida no ato da concretização da obra.

Este prolongado esforço não pode se materializar e assim sendo, não garante a concretização destas idéias, só do ato do assassinato e de todos os aspectos que circundam este fato. Tanto as sensações e desejos, que foram o motor da própria obra, quanto à vaidade, motor desta existência humana, se perdem com a morte do autor. Esta é a demarcação do que ascende à esfera pública e do que fica na esfera privada. Para o próprio autor, esta distinção pode não ter significado, bem como para o leitor interessado em garantir o preenchimento de seu ócio. Mas para a existência em sociedade, isto faz uma grande diferença. A concretização do mundo se dá pela garantia da aparência na esfera comum, à vista de todos, mas neste caso, ocorreu a partir de aspectos temáticos e motivações que, em sua essência são fugazes, não se concretizam, pois se direcionam ao consumo. Como resultado, corremos o risco de incessantemente não garantirmos a realização do mundo, sua concretude, constituindo, em oposição a isto, um grande universo onírico voltado, por um lado, para a mais completa subjetividade e, por outro, para a incessante busca pelo prazer.

Só a existência de uma esfera pública e a subseqüente transformação do mundo em uma comunidade de coisas 
que reúne os homens e estabelece uma relação entre eles depende inteiramente da permanência. Se o mundo deve conter um espaço público, não pode ser construido apenas de uma geração e planejado somente para os que estão vivos: deve transcender a duração da vida de homens mortais. (Arendt, 2000, p.64)

Incapacitado de aparecer como sujeito, este homem acaba por perder a noção do e sobre o mundo, gerando como conseqüência a incapacidade, num segundo momento, de julgar o próprio mundo. Este começa por se desrealizar e o homem torna-se absolutamente supérfluo.

\section{Bibliografia}

ARENDT, Hannah.A Condição Humana. RJ: Forense Universitária, $10^{\mathrm{a}}$ edição, 2000.

Homens em Tempos Sombrios. S.P.: Companhia das Letras, 1990.

BAITELLO JUNIOR, Norval; CONTRERA, Malena Segura; MENEZES, José Eugênio de O.( orgs). Os Meios da Incomunicação. São Paulo: Annablume; CISC, 2005.

CONTRERA, Malena Segura; FIGUEIREDO, Roali Rossi; REINERT, Leila. Jornalismo e Realidade. São Paulo: Editora Machenzie, 2004.

HABERMAS, Jürgen. Mudança Estrutural da Esfera Pública. RJ:Tempo Universitário, 1984.

Filme

Capote. 2005. Bennett Miller.EUA, Columbia Pictures, 98 min., legendado, color.

Consulta a internet

Site oficial do filme. www.sonyclassics.com/ capote 